\title{
Medical History Completion Date
}

National Cancer Institute

\section{Source}

National Cancer Institute. Medical History Completion Date. NCI Thesaurus. Code C83029.

The date on which the recording of the patient medical history was finished. 